\title{
Microencapsulation of passion fruit extract (Passiflora biflora) by spray drying
}

\author{
Aguilar, D. ${ }^{\text {a; }}$ Rodríguez, O. ${ }^{\text {a }}$ Luna, G..$^{\text {; }}$ Zarate G. ${ }^{\text {a }}$; Bello L. ${ }^{\text {* }}$ \\ a Technological University Center Veracruz, Av. Universidad Federal Highway 350. No Cuitláhuac \\ La Tinaja. Location Two roads CP 94910, Cuitlahuac, Veracruz, Mexico. \\ ${ }^{\mathrm{b}}$ Department of Graduate Studies and Research, Technological Institute of Orizaba Oriente, Av. 9 \\ No. 852, Col. Emiliano Zapata, CP 94320, Orizaba, Veracruz, Mexico. \\ *E-mail of the corresponding author: licet.bello@utcv.edu.mx
}

\begin{abstract}
Anthocyanins pulp and peel passionfruit extracted by leaching using water as a solvent where the operating conditions of spray drying were evaluated for a microencapsulated. The variables were temperature input (180,200 and 220 $\circ \mathrm{C}), \mathrm{MD}$ (6,8y10\%), AP (1,3y5\%) and outlet temperature $80^{\circ} \mathrm{C}$, was achieved noted that during the drying process moisture decreased to $85 \%$ due to this high in MD and AP, this also increases the content of ST. Color significantly was not affected by spray drying..
\end{abstract}

Keywords: Passionfruit, abstract, encapsulants, spray microencapsulation. 


\section{Introduction}

Passionfruit (Passiflora biflora) is a wild fruit ovoid neotropical as shown in (Fig 1) and belongs to the Passifloraceae family, is a liana with smooth variable leaves are generally wider than long, with two lobes that occur with the cut end, rounded or slightly stippled. [n1] In recent years it has sought ways to replace artificial pigments thus has opted for extraction of certain natural pigments from different plants and fruits, is why in the present research, the extraction process is evaluated own compounds of passion fruit by microencapsulation technique by spray drying.

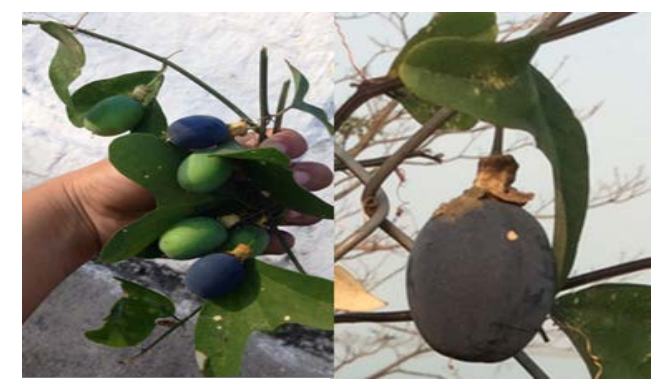

Fia. 1 Passiflora biflora

Microencapsulation by spray drying corresponds to the transformation of a fluid into a solid material, shaped by atomizing minute droplets into a hot drying medium. One of the great advantages of this process, besides its simplicity, is suitable for heat sensitive materials because the exposure time at elevated temperatures is very short ranging between 5 and 30 seconds [n3, n5]. Anthocyanins belong to the flavonoid family, composed of two aromatic rings, a and $\beta$ joined by a chain of 3 carbons [n2], these pigments are widely distributed in fruits and flowers, offering attractive colors such as orange, red and blue [n6]. One of the most important and studied food characteristics is the color,the Interest in anthocyanin pigments in scientific research have increased in recent years, due not only to the color that give products that contain them but its likely role in reducing heart disease, cancer, diabetes, anti-inflammatory, improvement of visual acuity and cognitive performance; these preventive and therapeutic effects are mainly associated with its antioxidant properties [n4] The objective of this research was microencapsulated anthocyanins pulp and peel passion fruit by spray drying with maltodextrin and potato starch, evaluating the influence of the conditions drying. 


\section{Materials and Methods}

\subsection{Raw material}

Passionfruit (Passiflora Biflora) was harvested and collected in the high mountains, Cordoba, Veracruz, Mexico

\subsection{Fruit packaging.}

The fruit was placed at room temperature $\left(25^{\circ} \mathrm{C}\right)$ for 2 hours to return to its initial state, the subsequent detachment of the peduncle performed and seed making a homogenization between the pulp and peel of the fruit into a sterile glass papillary.

\subsection{Extraction of anthocyanins.}

Once homogeneous mixture extraction was performed by placing the fruit in water at $30^{\circ}$ $\mathrm{C}$ for 2 hours, to obtain the anthocyanins in the solvent, filtration was performed on Whatman paper to remove solids from the extract.

\subsection{Experimental design.}

The amounts used were determined by an Box-Behnken experiment design have three variables to consider: Inlet temperature, \% maltodextrin and potato starch \%.

Box-Behnken desingns always have 3 levels per factor, is a type of design response surface that does not have an embedded fractional factorial designt, where the design points are in combinations of high and low levels of factors and their midpoints [n8].

\subsection{Determination of moisture.}

Moisture determination of passion fruit extract was performed in a thermobalance of Sartorius, Model MA35 brand. At a temperature of $121^{\circ} \mathrm{C}$.

\subsection{Determination of Total Solids.}

It was determined by weight difference according to the result of \% moisture.

\subsection{Determination of color.}

The color measurement was performed to extract Colorquest XE colorimeter for liquids where "L", "a” and "b" values were obtained. Determining color for dry passionfruit was performed with a colorimeter MiniScan XE plus the mark Hunterlab obtaining values "L", "a" and "b".

\subsection{Determination of water activity (aw).}

The water activity (aw) was measured with an Aqualab, model series 3 computer. 


\section{Results and discussions}

\subsection{Fruit Yield}

In (Table 1). integral yield mature fruit, which is formed by $8 \%$ shell, $80 \%$ pulp and $10 \%$ seed and the other $2 \%$ is the organic waste [n1] is shown.

Table 1. Performance passionfruit (Passiflora biflora)

\begin{tabular}{cccccccc}
\hline Sample & $\begin{array}{c}\text { Total } \\
\text { weight } \\
\mathbf{( g )}\end{array}$ & $\begin{array}{c}\text { Pulp } \\
\text { weight } \\
\mathbf{( g )}\end{array}$ & $\begin{array}{c}\text { Seed } \\
\text { weight } \\
\mathbf{( g )}\end{array}$ & $\begin{array}{c}\text { Shell } \\
\text { weight } \\
\mathbf{( g )}\end{array}$ & $\begin{array}{c}\text { Shell yield } \\
\mathbf{( \% )}\end{array}$ & $\begin{array}{c}\text { Seed yield } \\
\mathbf{( \% )}\end{array}$ & $\begin{array}{c}\text { Pulp yield } \\
\mathbf{( \% )}\end{array}$ \\
\hline A & 104.5698 & 83.5903 & 9.8471 & 7.7998 & 7.4589 & 9.4167 & 79.9377 \\
\hline B & 108.6584 & 86.6302 & 9.2321 & 8.5462 & 7.8651 & 8.4964 & 79.7271 \\
\hline C & 112.9454 & 87.5682 & 10.9358 & 8.5821 & 7.5984 & 9.6823 & 77.5314 \\
\hline
\end{tabular}

Source: [n1]

Table 2. Results obtained from the extract in different concentrations

\begin{tabular}{cccccc}
\hline Sample & $\begin{array}{c}\text { Temperature } \\
\left({ }^{\circ} \mathrm{C}\right)\end{array}$ & $\begin{array}{c}\text { Maltodextrin } \\
(\% \mathrm{~m} / \mathrm{v})\end{array}$ & $\begin{array}{c}\text { Potato Starch } \\
(\% \mathrm{~m} / \mathrm{v})\end{array}$ & $\begin{array}{c}\text { Humidity } \\
(\%)\end{array}$ & $\begin{array}{c}\text { ST } \\
(\%)\end{array}$ \\
\hline 1 & 180 & 6 & 3 & 92.11 & 7.89 \\
2 & 180 & 10 & 3 & 87.81 & 12.19 \\
3 & 220 & 6 & 3 & 91.71 & 8.29 \\
4 & 220 & 10 & 3 & 85.83 & 14.17 \\
5 & 180 & 8 & 1 & 87.64 & 13.36 \\
6 & 180 & 8 & 5 & 90.30 & 9.70 \\
7 & 220 & 8 & 1 & 90.81 & 9.19 \\
8 & 220 & 8 & 5 & 87.81 & 12.19 \\
9 & 200 & 6 & 1 & 89.05 & 10.95 \\
10 & 200 & 6 & 5 & 86.85 & 13.15 \\
11 & 200 & 10 & 1 & 91.82 & 8.18 \\
12 & 200 & 10 & 5 & 82.12 & 17.88 \\
13 & 200 & 8 & 3 & 86.23 & 13.77 \\
14 & 200 & 8 & 89.22 & 10.78 \\
15 & 200 & & 3.56 & 10.44 \\
\hline
\end{tabular}


In (Table 2). Results show the humidity and ST obtained extract at different concentrations which shows that the amount of maltodextrin and starch added potato is directly proportional to the \% obtained, showing that the higher the added amount increases occurs in solids and a decrease moisture.

In (Fig. 2) is observed that a high level of MD and an average level of AP the highest content of total solids in the samples are present, this may be due to the degree of solubility of potato starch samples, since increasing this concentration could suffer saturation in the solution, affecting the homogeneity of the sample.

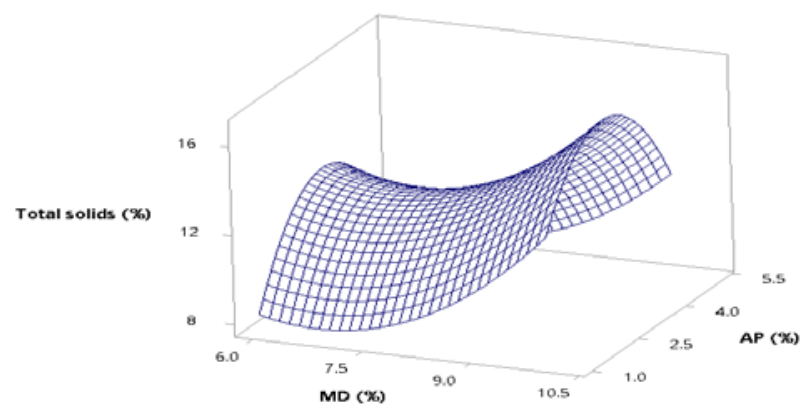

Fig. 2. Correlation of TS content

In (Fig. 3) the graphical response surface moisture, it is clear that its content decreases until $85 \%$ with a content of, high MD and low AP, as the one that is shown to microencapsulated ascorbic acid by spray drying with two matrices maltodextrin and soluble potato starch, the moisture value reported is $0.038 \pm 1.5 \%$, which is low by these drying conditions.[n9]

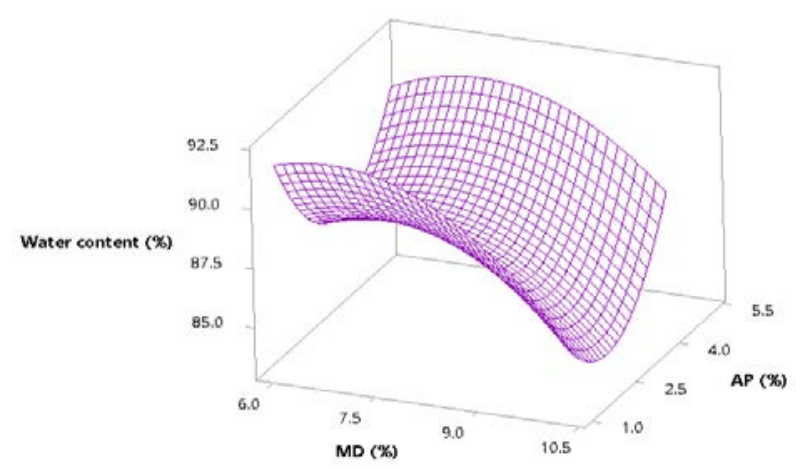

Fig 3. Correlation of moisture content

In (Table 3) results according to the color parameters are shown, the luminosity (L), chromaticity $\left(a^{*}, b^{*}\right)$ in the extract, the changes $(\mathrm{L})$ clearly observed were diminished as 
was increased the number of solids, however parameters $(\mathrm{a} * \mathrm{~b} *)$ had a trend toward red and blue, which notes the presence of anthocyanins which are responsible for the red, orange, blue and purple colors fruits, flowers and other plant products.

Table 3.- Results of chromaticity in different concentrations extract

\begin{tabular}{cccc}
\hline \multirow{2}{*}{ Sample } & \multicolumn{3}{c}{ Chromatic parameters } \\
\cline { 2 - 4 } 1 & $\mathrm{~L}$ & $\mathrm{a}$ & $\mathrm{b}^{*}$ \\
\hline 2 & 1.71 & -0.05 & -0.35 \\
3 & 1.46 & -0.43 & -0.17 \\
4 & 1.26 & -0.34 & -0.07 \\
5 & 1.21 & -0.39 & -0.43 \\
6 & 1.39 & -0.29 & -0.05 \\
7 & 1.45 & -0.90 & 0.20 \\
8 & 1.34 & -0.66 & -0.74 \\
9 & 1.38 & -0.17 & -0.29 \\
10 & 1.47 & -0.52 & -0.30 \\
11 & 1.31 & -0.25 & 0.13 \\
12 & 1.69 & -0.91 & 0.13 \\
13 & 1.43 & -0.28 & -0.14 \\
14 & 1.57 & -0.80 & 0.06 \\
15 & 1.31 & -0.40 & -0.31 \\
& 0.83 & -0.90 & -0.71 \\
\hline & & & \\
\hline
\end{tabular}

Table 4. Results obtained after performing spray drying

\begin{tabular}{clll}
\hline Sample & H $(\%) \pm$ DS & ST $(\%) \pm$ DS & aw \pm DS \\
\hline 1 & $5.04 \pm 0.06$ & $94.97 \pm 0.06$ & $0.308 \pm 0.03$ \\
2 & $7.07 \pm 0.64$ & $92.94 \pm 0.64$ & $0.411 \pm 0.01$ \\
3 & $5.06 \pm 0.18$ & $94.94 \pm 0.18$ & $0.308 \pm 0.03$ \\
4 & $5.15 \pm 0.12$ & $94.86 \pm 0.12$ & $0.345 \pm 0.01$ \\
5 & $8.28 \pm 0.49$ & $91.72 \pm 0.49$ & $0.380 \pm 0.01$ \\
6 & $6.87 \pm 0.19$ & $93.14 \pm 0.19$ & $0.327 \pm 0.01$
\end{tabular}

In (Table 4) the results obtained are shown after performing spray drying which shows that in runs 3 and 4 there is a lower moisture content $5.06 \%$ and $5.15 \%$ respectively, resulting in 
a greater amount of ST, is therefore it is considered that in a matter of performance is optimal to use an amount of maltodextrin $10 \%$ because this presents better results.

In (Table 5) color results obtained in the pigment are shown, where the parameters (L, $\mathrm{a}^{*}, \mathrm{~b}$ *) had a color trend toward red and blue resulting in the run, number 2 and 6 have a higher intensity is the color, which results show the presence of anthocyanins, demonstrating that the spray drying does not alter the anthocyanins present in the fruit.

Table 5. Results of chromaticity obtained after performing spray drying

\begin{tabular}{cccc}
\hline \multirow{2}{*}{ Sample } & \multicolumn{3}{c}{ Chromatic parameters } \\
\cline { 2 - 4 } & $\begin{array}{c}\text { Luminosity } \\
\text { L } \pm \text { DS }\end{array}$ & $\begin{array}{c}\text { Chromaticity } \\
\text { a } \pm \text { DS }\end{array}$ & $\begin{array}{c}\text { Chromaticity } \\
\text { b } \pm \text { DS }\end{array}$ \\
\hline 1 & $46.87 \pm 0.21$ & $6.65 \pm 0.13$ & $-5.16 \pm 0.05$ \\
2 & $42.50 \pm 0.18$ & $8.36 \pm 0.04$ & $-3.14 \pm 0.19$ \\
3 & $39.95 \pm 0.21$ & $5.45 \pm 0.49$ & $-3.06 \pm 0.08$ \\
4 & $45.42 \pm 0.49$ & $5.18 \pm 0.04$ & $-2.35 \pm 0.21$ \\
5 & $46.06 \pm 0.44$ & $7.37 \pm 0.21$ & $-1.60 \pm 0.47$ \\
6 & $44.22 \pm 0.30$ & $8.26 \pm 0.10$ & $-1.73 \pm 0.49$ \\
\hline
\end{tabular}

\section{Conclusions}

From the extract obtained color leached from fruit of the passion fruit one microoencapsulado product was achieved maltodextrin by spray drying, where according to the experiment performed and the results obtained it is established that the optimum conditions for the pigment are the runs 3 and 4 with an inlet temperature of $180^{\circ} \mathrm{C}$, MD $10 \% \mathrm{D} 10,5.1 \%$ of $\mathrm{AP}$ and a temperature of $80^{\circ} \mathrm{C}$ outlet, because in these higher performances are obtained and although They do not exhibit the greatest color intensity but they present a good one, which represents the existence of anthocyanins, which makes them be suitable for obtaining the pigment by spray drying. 


\section{Nomenclature}

$\begin{array}{ccc}\text { L } & \text { Luminosity } \\ \mathrm{a}^{*} \mathrm{y} \mathrm{b}^{*} & \text { Chromaticity } & \\ \mathrm{H} & \text { Humidity } & \% \\ \text { ST } & \text { Total solids } & \% \\ \text { MD } & \text { Maltodextrin } & \% \\ \text { AP } & \text { Potato starch } & \% \\ \text { aw } & \text { Water activity } & \%\end{array}$

\section{References}

[1] Aguilar, Daniela, and others. "Morphology and physicochemical characterization of the passion fruit (Passiflora biflora)." Mexico Research Center (2017).

[2] Arrazola, Guillermo, Irina Herazo, and Armando Alvis. "Microencapsulation of anthocyanins Eggplant (Solanum melongena L.) by spray drying and Evaluation of color stability and antioxidant capacity." Research Group Process and Plant AgroIndustry (2014): 31-42.

[3] Hernández, Oreste Dario Lopez. " Oily substances microencapsulation by spray drying.» Cuban Journal of Pharmacy (2010): 381-389.

[4] Pastrana, Karla Guadalupe Lopez, et al. "Microencapsulation of natural pigments obtained from the peel and pulp of fruits of Opuntia spp.» Newsletter ICAP Agricultural Sciences (2017).

[5] Poveda, Maria Jose Tapia. Ascorbic Acid microencapsulation by spray drying with starch and maltodextrin. Ecuador, 2017.

[6] Prieto, Gerardo Avendano and Buitrago Baudilio Acevedo. "Microencapsulation process of natural dyes in strawberry (Fragaria vesca)." Ontare (2014): 7-34.

[7] Yepez, José Luis Villacrez. Development of microencapsulated by spray drying from blackberry fruits (Rubus glaucus Benth). Colombia, 2013.

[8] Montgomery, Douglas C. Design, and analysis of experiments. Mexico DF: Limusa SA de CV, 2005.

[9] Palma Rodriguez, Hugo Miguel, and others. "Ascorbic acid microencapsulation by spray-drying in native and acid-modified starches from different botanical sources." (2013) 65, 584-592. 